\title{
The roles of dispersal limitation and environmental conditions in controlling caddisfly (Trichoptera) assemblages
}

\author{
VICTOR LEMES LANDEIRO*, ${ }^{*}$, LUIS MAURICIO BINI ${ }^{+}$, ADRIANO SANCHES MELO $^{+}$, ANA MARIA \\ OLIVEIRA PES $\ddagger$ AND WILLIAM ERNEST MAGNUSSON* \\ *Programa de Pós Graduação em Ecologia, Instituto Nacional de Pesquisas da Amazônia, Manaus, Brazil \\ ${ }^{\dagger}$ Departamento de Ecologia, ICB, Universidade Federal de Goiás, Goiânia, Brazil \\ ${ }^{\ddagger}$ Coordenação de Biodiversidade, Instituto Nacional de Pesquisas da Amazônia, Manaus, Brazil
}

\section{SUMMARY}

1. Many recent studies have quantified the relative importance of environmental variables and dispersal limitations in shaping the structure of stream communities. However, the relative importance of these factors at different spatial extents has been seldom evaluated.

2. We analysed the distribution of caddisfly species in 89 Amazonian streams in relation to stream characteristics and spatial variables representing overland dispersal routes. The streams occur in three regions that differ in spatial extent and environmental characteristics. We analysed the data using partial redundancy analysis with two predictor data sets, one environmental and one spatial, to evaluate the variation in assemblage composition. We also separated caddisflies into 'good' and 'poor' dispersers to evaluate possible differences in the responses of these two groups. 3. The environmental component explained a higher proportion of variance in assemblage composition than did the spatial component. Spatial effects were evident only when data from all three regions were analysed together, although the exclusive spatial fraction was quite low. Good dispersers responded similarly to the community as a whole, while poor dispersers were related to environmental variables only in one region and also were not related to spatial variables.

4. Caddisflies were most affected by environmental factors. The large environmental effect and small spatial effect are in accord with the use of these stream insects as good indicators of site properties and disturbances in monitoring programmes.

Keywords: Amazonia, metacommunities, neotropical streams, redundancy analysis, spatial analysis

\section{Introduction}

Environmental heterogeneity is assumed to be of paramount importance in regulating the community structure of stream macroinvertebrates. For instance, variability in substratum, water current, stream depth biotic interactions and frequency of spates are important factors influencing stream biota over a range of spatial scales (Clausen \& Biggs, 1997; Bond \& Downes, 2000; Olsen, Townsend \& Matthaei, 2001). In addition, owing to the generally higher connectivity and dispersal potential within drainages, stream communities there may be more similar than those in streams in different drainages. High similarity among communities inhabiting neighbouring streams may result from both environmental similarity and the limited ability of species to disperse to distant streams in a metacommunity context.

The environmental control model (sensu Borcard, Legendre \& Drapeau, 1992), currently known as the species sorting paradigm (Leibold et al., 2004), emphasises the importance of the set of local factors in shaping community structure. On the other hand, the effect of dispersal limitation is encapsulated by the neutral paradigm, which assumes that all species in a metacommunity

Correspondence: Victor Lemes Landeiro, Programa de Pós Graduação em Ecologia, Instituto Nacional de Pesquisas da Amazônia, CP 478, Manaus, AM, CEP: 69011.970, Brazil. E-mail: vllandeiro@gmail.com 
are ecologically equivalent and that differences between local communities are generated by random processes of mortality and colonisation (Hubbell, 2001). However, Thompson \& Townsend (2006) challenged this simplistic dichotomy and emphasised that, depending on dispersal ability and trophic level, the structure of local communities can be explained by both dispersal processes and local environmental conditions. Note also that first attempts in the development of metacommunity theory envisaged the possibility of other paradigms (i.e. patch dynamic and mass effects; Leibold et al., 2004; Cottenie, 2005; Logue et al., 2011).

Variation partitioning methods are frequently used to infer the relative importance of environmental factors and spatial variables in explaining the structure of biological assemblages (e.g. Peres-Neto et al., 2006; Peres-Neto \& Legendre, 2010 and references therein). Partitioning of variation in assemblage data uses the species-data table as the response variable and environmental and spatial variables as predictors. Space is usually represented by a symmetric geographical distance matrix $\mathbf{D}$ containing $n(n-1) / 2$ elements (where $n$ is the number of sites). This matrix can be analysed directly using partial Mantel tests (distance approach; Tuomisto \& Ruokolainen, 2006), but it is also possible to convert this matrix into orthogonal variables of length $n$, allowing analysis of species-assemblage data in its original form (the raw-data approach; Legendre, Borcard \& Peres Neto, 2005). The raw-data approach is usually based on eigenfunction analysis (Peres-Neto \& Legendre, 2010; Landeiro \& Magnusson, 2011), which is considered the most flexible way to recover spatial patterns in data (but see Landeiro et al., 2011). Eigenfunction analysis produces eigenvectors associated with large, intermediate and small eigenvalues that represent, respectively, landscape-wide trends (e.g. global), medium scales (e.g. regional) and fine scales or patchiness (e.g. local). This flexibility comes at a cost for interpretation, but these methods are well suited to generate proxy spatial variables to represent dispersal and/or unmeasured environmental variables, which may be structured at different spatial scales (Blanchet, Legendre \& Borcard, 2008b; Landeiro et al., 2011).

Caddisfly (Trichoptera) larvae have been frequently used in monitoring programmes as bioindicators of organic pollution (e.g. Couceiro et al., 2007). Also, they play important roles in food webs (Vannote et al., 1980) and ecological processes such as leaf breakdown (Landeiro, Hamada \& Melo, 2008; Landeiro et al., 2010). Caddisflies are commonly used as bioindicators because of their close relationship to environmental conditions (Rosenberg \& Resh, 1993) and because they are good dispersers at local scales (Collier \& Smith, 1998; Bilton, Freeland \& Okamura, 2001), which might minimise distance effects and spatial patterns. The dispersal of caddisflies may also be affected by other traits, such as differences in the means of dispersal of larval (downstream drift) and adult stages (upstream and lateral flight). The importance of lateral flight of adults may differ in magnitude according to the density of the vegetation matrix that they need to cross, and the upstream corridor is considered the main pathway for adult dispersal (Petersen et al., 2004; but see Landeiro et al., 2011). However, there is a wide variation in dispersal distance among species, making any effort at generalisation precarious (e.g. Wilcock et al., 2007). In addition, the effects of distance depend on the spatial extent of the study, which in turn determines the length of many environmental gradients (Gilbert \& Lechowicz, 2004). Environmental impacts may be limited to local scales or may affect large regions. Therefore, the relative effects of distance and environment on community similarity should be evaluated over multiple spatial scales (Brown et al., 2011).

We investigated the effects of spatial extent on the structure of assemblages of caddisfly larvae in 89 Amazonian streams in three regions near Manaus (Brazil). These regions vary in spatial extent and in the spatial arrangement of sampling sites. We hypothesised that the importance of environmental and spatial variables would be higher in the analyses including all data than in analyses of the data for each region separately. We expected that environmental heterogeneity would increase with spatial extent and that assemblage composition would be better predicted by spatial variables in regions of large spatial extent. Conversely, data sampled at broader scales should reveal higher environmental heterogeneity and stronger spatial effects (the latter owing to increased effects of dispersal limitation). We also reran all analyses after dividing the response matrix into matrices containing the species present in the three regions (common species) and the species present exclusively in a given area (exclusive species). By doing so, we attempted to test two complementary predictions. First, the distribution of common species should be mainly related to environmental factors, as it is unlikely that dispersal limitation plays an important role in this context. Second, exclusive species should be more related to spatial than to environmental variables, as these species were not found in all regions. 


\section{Methods}

\section{Study area}

The data used in this study were obtained between April 2002 and February 2003 from 89 stream sites in Central Amazonia. We sampled black-water streams (i.e. streams with dark water caused by humic and fulvic acids leaching from decomposing leaves) in areas that are not seasonally flooded (called 'terra firme' forests in the Amazonian literature). In general, streams in Central Amazonia are characterised by nutrient-poor, acid waters, and low daily and annual variation in water temperature, with annual and daily means close to $25^{\circ} \mathrm{C}$ (Sioli, 1984).

We sampled immature caddisflies at 89 sites distributed in three regions (Fig. 1). The first region included 39 sites in the Ducke Reserve (hereafter DR; $02^{\circ} 57^{\prime} \mathrm{S}$; $59^{\circ} 55^{\prime} \mathrm{W}$ ), a $10 \times 10 \mathrm{~km}$ area on the edge of the city of Manaus. The second region is maintained by the Biological Dynamics of Forest Fragments Project (hereafter BD) located about $70 \mathrm{~km}$ north of Manaus $\left(02^{\circ} 26^{\prime} \mathrm{S}\right.$; $\left.59^{\circ} 46^{\prime} \mathrm{W}\right)$. The BD comprises areas of old-growth and regrowth forests, as well as pastures. We obtained samples from 20 streams in the BD region. The third region was the municipality of Presidente Figueiredo (hereafter PF), located about $120 \mathrm{~km}$ north of Manaus $\left(02^{\circ} 01^{\prime} \mathrm{S}\right.$; $\left.60^{\circ} 01^{\prime} \mathrm{W}\right)$, where we sampled 30 streams. The spatial extents (the geographical distance between the sites farthest from each other) within each region were about $10 \mathrm{~km}$ at DR, $40 \mathrm{~km}$ at $\mathrm{BD}$ and $100 \mathrm{~km}$ at the PF regions (Fig. 1).

Most streams in DR and BD have sandy bottoms, while those in PF have bedrock and stones (boulders, cobbles, pebbles and gravel) in addition to sand. Streams in PF have fast-flowing waters and many waterfalls, located on an ancient Tertiary plateau that is responsible for the sloped relief in relation to the more geologically recent, lowelevation Quaternary formations underlying BD and DR.

\section{Sampling}

We defined three sample units of $2.25 \mathrm{~m}^{2}$ at least $5 \mathrm{~m}$ apart within a stream reach of $50 \mathrm{~m}$ and sampled all substrata available in each of the three sample units, using a D-net (mesh size of $250 \mu \mathrm{m}$ ). In some cases, where the main substratum was composed of bedrock, we used a Surber sampler with the same mesh size. Caddisflies attached to bedrock and stones were removed using tweezers and spatulas. Samples were stored in plastic bags and fixed in $96 \%$ ethyl alcohol. In the laboratory, the caddisflies were sorted under a stereomicroscope and assigned to morphospecies or, when possible, to species.

Physical and chemical variables were also measured at each site. Water temperature was measured using a handheld thermometer. Electrical conductivity and $\mathrm{pH}$ were measured with a portable conductivity and $\mathrm{pH}$ meter, respectively. Water velocity $\left(\mathrm{V} ; \mathrm{cm} \mathrm{sec}^{-1}\right)$ was estimated using the method described by Craig (1987). Stream discharge $(D)$ was estimated as $D=W \times D \times V$, where $W$ is stream width $(\mathrm{m})$ and $D$ is stream depth $(\mathrm{m})$. The proportion of each substratum type [woody debris, leaves, roots, sand, macrophytes, stones (cobbles, pebbles and gravel) and bedrock] was estimated visually, following the method described by McCreadie \& Colbo (1991).

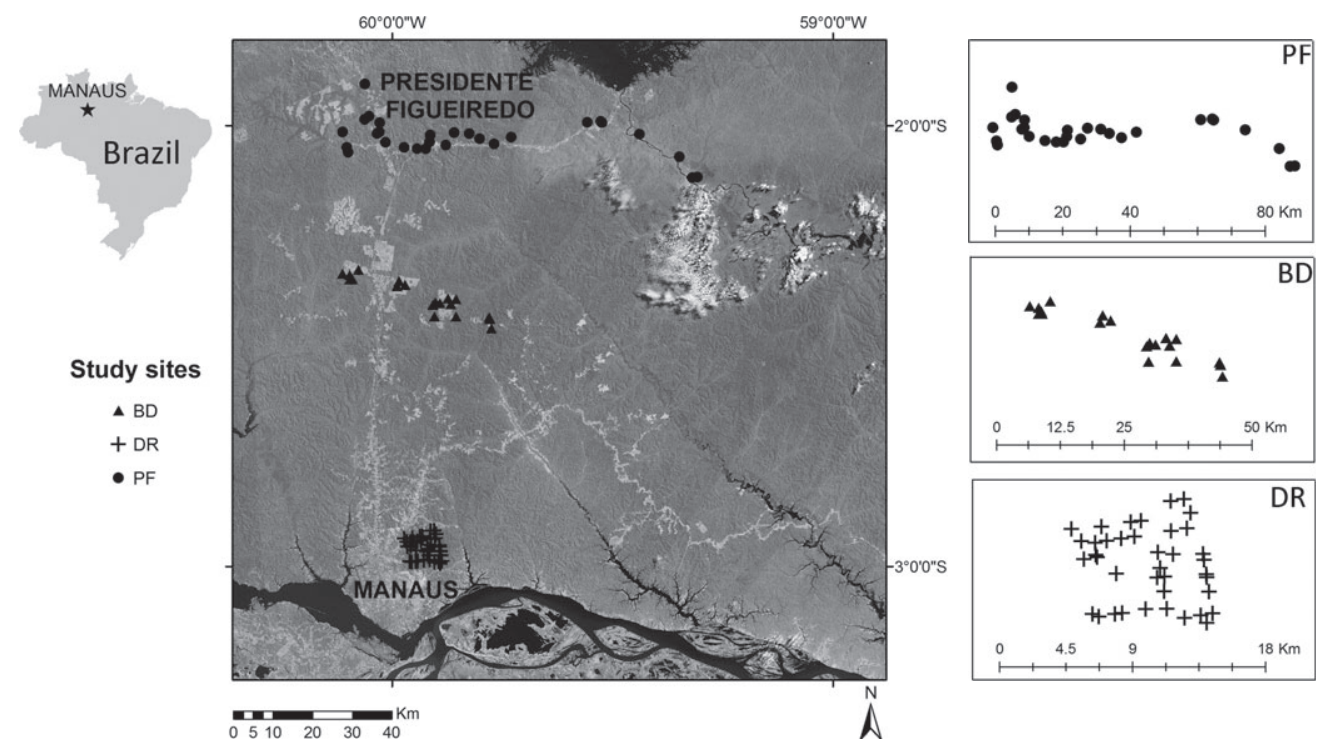

Fig. 1 Map of Brazil and geographical locations of sampling sites. Ducke Reserve (DR - +), Presidente Figueiredo (PF - $\bullet$ ) and the reserves of the Biological Dynamics of Forest Fragments Project (BD - $\mathbf{\Delta}$ ). Each right-hand panel shows the sampling sites in each region in detail. 


\section{Data analysis}

To test whether environmental heterogeneity differed between regions, we used analysis of homogeneity of multivariate dispersions (hereafter PERMDISP). PERMDISP is a multivariate analogue of Levene's test for homogeneity of variances, and the statistic (average distance of group members to the group centroid) is tested by permutation (Anderson, 2006). In addition, we tested whether environmental characteristics differed between regions, using a nonparametric multivariate analysis of variance (npMANOva; Anderson, 2001). Environmental data (except $\mathrm{pH}$ ) were log-transformed before analysis. Data in percentages were transformed to arcsine square root. Afterwards, we standardised all variables to mean zero and unit variance. Euclidean distances based on standardised environmental data were used in the PERMDISP and nPMANOVA.

Using the $\log (x+1)$ abundance data, we calculated the Bray-Curtis index to represent dissimilarity in species composition among streams. When using assemblage dissimilarities, the average distance to the group centroid (i.e. multivariate dispersion) is a measure of overall species turnover, or beta-diversity in the region (Anderson, Ellingsen \& McArdle, 2006). Therefore, we used the PERMDISP to evaluate whether beta-diversity differed between the regions (i.e. differences in multivariate dispersions). Tukey's test was used for pairwise comparisons between regions. We also used npMANOva to test whether species composition differed between regions.

Although in-stream dispersal through larval drift and upstream adult flight are well recognised for caddisflies (e.g. Petersen et al., 2004), they also disperse overland in the adult stages. Indeed, we have shown elsewhere (Landeiro et al., 2011) that for Trichoptera, there is no difference between overland and watercourse distance (actually, overland distance performed slightly better). Thus, a matrix of Euclidean (overland) distances between sample sites is likely to provide adequate descriptors of dispersal routes and spatial patterns (Landeiro et al., 2011). We analysed the data using the raw-data approach (Legendre et al., 2005), through a partial redundancy analysis (pRDA) to evaluate the relative contributions of environmental and spatial variables to assemblage patterns. The spatial variables used in the pRDA were obtained by means of an eigenfunction analysis using principal coordinates of neighbour matrices (PCNM; Borcard \& Legendre, 2002). The PCNM approach uses a truncated matrix of geographical distances in a principal coordinates analysis to generate the spatial variables that represent spatial patterns ranging from broad (low-order PCNMs) to fine scales (high-order PCNMs). After the creation of the spatial variables, we ran separate RDA models for environmental and spatial variables and evaluated the significance of these models. In the cases where the full model was statistically significant (as indicated by 9999 Monte Carlo permutations), we used a forward selection procedure (Blanchet, Legendre \& Borcard, 2008a) to retain only the spatial and environmental variables most related to caddisfly assemblages to be used in the pRDA. By using pRDA, we obtained the components of variance explained exclusively by the environmental variables [a], by the environmental variables that are spatially structured $[b]$, uniquely by the spatial variables [c] and the unexplained variance $[\mathrm{d}]$. We ran the pRDA and variance partitioning for data from all regions combined and separately for each region. Values of variance partitioning reported for pRDA are adjusted $R^{2}$ (Peres-Neto et al., 2006). The inclusion or exclusion of rare species in multivariate analyses is often debatable (e.g. Cao, Larsen \& Thorne, 2001); therefore, we analysed the data removing species that occurred in one to ten streams to evaluate the stability of our results.

We reran all partial redundancy models after dividing the response matrix into matrices containing the species present in the three areas (common species) and the species present exclusively in a given area (exclusive species). All analyses were conducted using the vegan (Oksanen et al., 2011) and packfor (Dray, Legendre \& Blanchet, 2009) libraries available for the $\mathrm{R}$ environment for statistical computing (R Development Core Team, 2011).

\section{Results}

We collected a total of 98 morphospecies, 69 from DR, 85 from $\mathrm{PF}$ and 69 from BD. The average number of species per stream was 22.5, ranging from 2 to 39 . On average, DR streams had more species per stream than PF and BD streams (Table 1). The number of exclusive species was highest in PF (18) and much lower in DR (8) and BD (4). Fifty-one species occurred in all three areas.

\section{Environmental and biological differences between the regions}

Assemblage composition and environmental characteristics differed between regions (npMANOva; $F_{2,86}=8.07$, $F_{2,86}=29.82$, respectively, $\left.P<0.001\right)$. Environmental characteristics (Fig. 2a,b) also differed between regions (PERMDISP, $F_{2,86}=8.30, P<0.001$ ), where PF was the 
Table 1 Mean $( \pm \mathrm{SD})$ distances to the group centroid in the analysis of homogeneity of multivariate dispersions

\begin{tabular}{llll}
\hline & $\mathrm{DR}$ & $\mathrm{BD}$ & $\mathrm{PF}$ \\
\hline $\begin{array}{c}\text { Spatial extent (decimal } \\
\text { degrees) }\end{array}$ & $0.03 \pm 0.01$ & $0.10 \pm 0.07$ & $0.19 \pm 0.17$ \\
$\begin{array}{c}\text { Environmental dispersion } \\
\begin{array}{c}\text { Assemblage composition } \\
\text { dispersion (Beta-diversity) }\end{array}\end{array}$ & $0.45 \pm 0.05$ & $0.49 \pm 0.07$ & $0.56 \pm 0.08$ \\
$\begin{array}{c}\text { Mean number of species } \\
\text { per stream }\end{array}$ & $24.6 \pm 6.0$ & $20.1 \pm 7.1$ & $21.6 \pm 6.9$ \\
\hline
\end{tabular}

Last row shows the mean number of species per stream in each region.

DR, Ducke Reserve; BD, Biological Dynamics of Forest Fragments Project; PF, Presidente Figueiredo County.

(a)

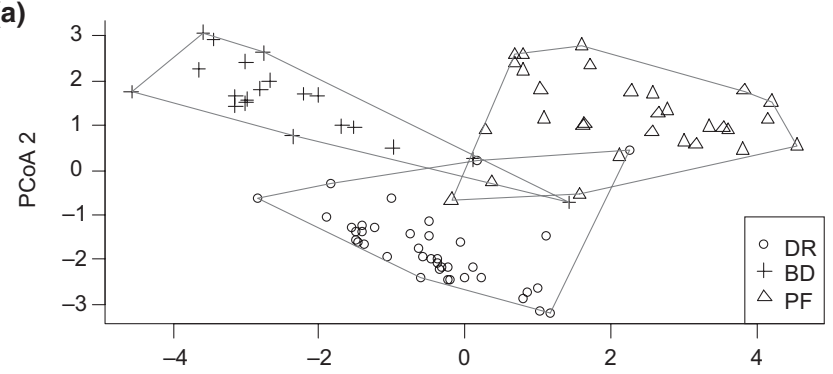

(b)

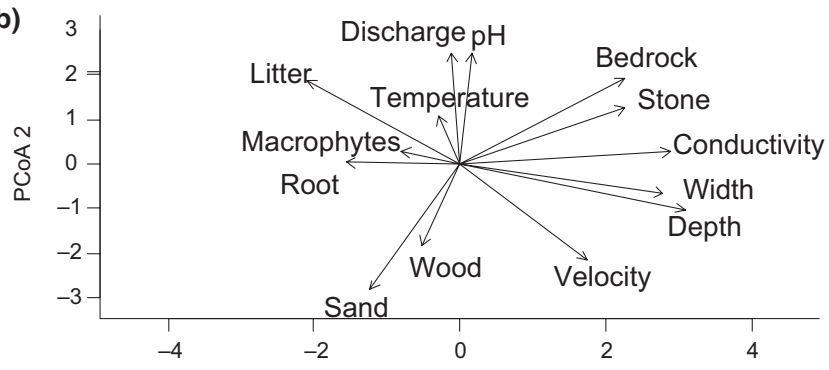

(c)

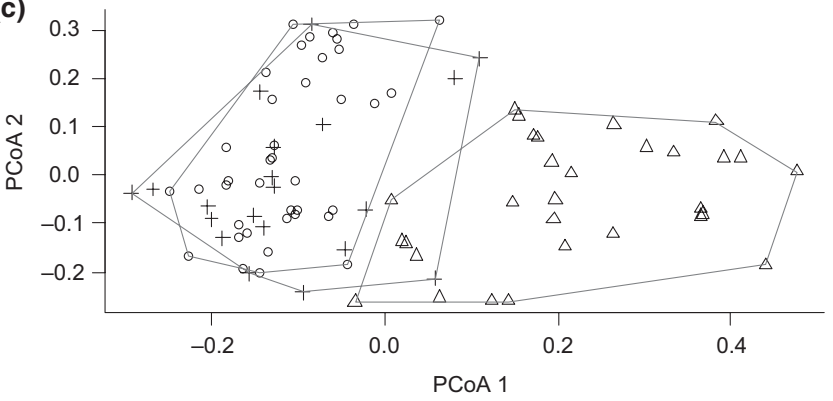

Fig. 2 Principal coordinates analysis (PCoA), used in the PERMDISP procedure, illustrating the differences in (a) environmental conditions, (b) relationship of environmental variables and PCoA axes shown in (a) and (c) assemblage composition. The assemblage composition observed in PF differed statistically from those of DR and BD. The environmental dissimilarity matrix used in the PCoA was calculated using the Euclidean distance on standardised environmental data. The assemblage dissimilarity matrix used in the PCOA was calculated on abundance data $(x)$ transformed to $\log (x+1)$. Polygons delimit samples from the same sample region. region with the highest environmental variability (average distance to centroid), followed by BD and DR (Table 1). However, PF and BD did not differ significantly in their environmental variability (Tukey's post hoc tests; $P=0.91$ ), indicating that these regions are similarly heterogeneous, while DR, the region with the lowest average distance to group centroid (i.e. lowest environmental heterogeneity), differed in environmental conditions from PF $(P<0.001)$ and from $\mathrm{BD}(P<0.013)$.

The average distance to the group centroid based on assemblage dissimilarities (i.e. species turnover or betadiversity) also differed between regions (PERMDISP, $F_{2,86}=14.73, P<0.001$, Fig. $\left.2 \mathrm{c}\right)$. PF had the highest average distance to the group centroid, followed by BD and DR (Table 1). PF differed significantly from BD and DR in average distance to the group centroid (Tukey's post hoc test; $P=0.005 ; P<0.001$; respectively), but $\mathrm{DR}$ and $\mathrm{BD}$ did not differ significantly.

\section{Variation in assemblage composition}

In accordance with the results provided by nPMANOva, the principal coordinates analysis showed a clear pattern differentiating caddisfly assemblage composition in PF streams from the other regions (Fig. 2c). For the pooled data set, the full environmental and the full spatial models (i.e. including all variables) were significant. The forward selection procedure retained 10 environmental variables and eight spatial variables in the reduced models (Table 2). At this large scale (the three regions together), $24.3 \%$ of the variance was explained by the predictor variables. The exclusive fraction explained by the environment [a] was $11 \%$ and the spatially structured environmental variation $[b]$ accounted for $9.5 \%$. There was a significant relationship with the spatial variables (fraction c), but they accounted for only $3.8 \%$ of the variance in assemblage composition. Caddisflies were sensitive to substratum type, and the streams with large areas of bedrock and macrophytes were distinct from other streams in the same region. The DR and BD streams differed in other environmental features (Fig. 2b), but these differences were not important in predicting assemblage composition.

The full spatial model was not significant for data from individual regions analysed separately (i.e. there were no significant spatial patterns within regions). On the other hand, the full environmental model was significant in all regions. At DR, three environmental variables (discharge, conductivity and percentage of stones) were retained in the reduced model, which explained $16.6 \%$ of the variance in assemblage data. At $\mathrm{BD}$, two environmental 
Table 2 Variation partitioning results based on partial redundancy analysis (RDA) analysis

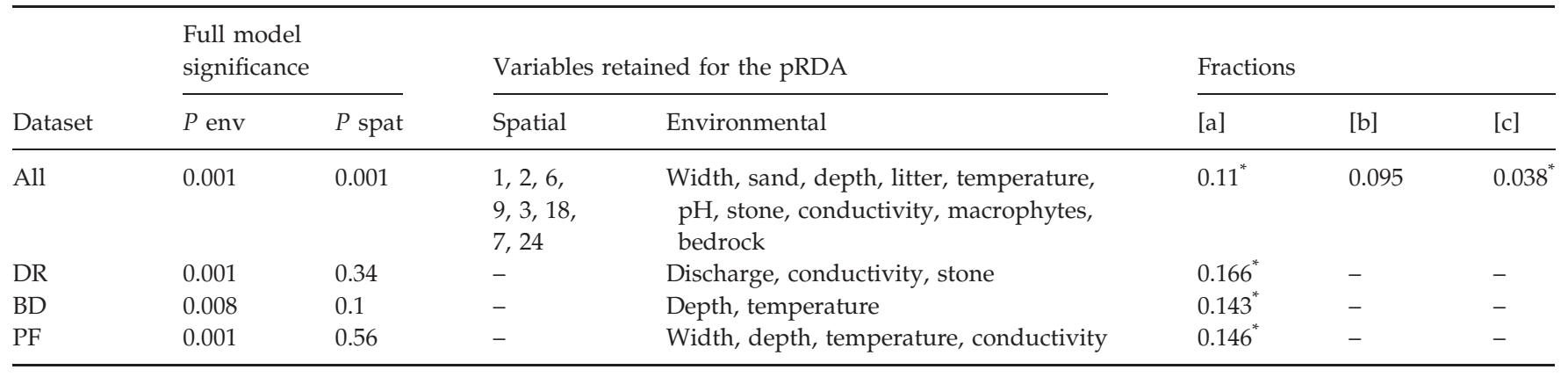

The final pRDA model includes variables retained with the forward selection procedure. Numbers for spatial variables indicate their order, where lower orders represent broad-scale patterns. $P$ spat and $P$ env give the significance for the full spatial and full environmental models (i.e. using all variables available). The spatial and environmental variables are shown in the order in which they were retained in the forward selection procedure. [a], environmental fraction; [b], shared fraction; [c], spatial fraction. The significance values for the environmental and spatial fractions are given. The full spatial models for DR, BD and PF are not significant, and therefore, forward selection was not performed. DR, Ducke Reserve; BD, Biological Dynamics of Forest Fragments Project; PF, Presidente Figueiredo County.

${ }^{*} P<0.001 ;-$, Full model not significant.

Table 3 Variation partitioning analysis of species tables, divided into exclusive species and species common to all regions

\begin{tabular}{|c|c|c|c|c|c|c|c|c|}
\hline \multirow[b]{2}{*}{ Dataset } & \multirow[b]{2}{*}{ Region } & \multicolumn{2}{|c|}{$\begin{array}{l}\text { Full model } \\
\text { significance }\end{array}$} & \multicolumn{2}{|c|}{ Variables retained for the pRDA } & \multicolumn{3}{|c|}{ Fractions } \\
\hline & & $P$ env & $P$ spat & Spatial & Environmental & [a] & [b] & [c] \\
\hline \multirow[t]{3}{*}{ Exclusive species } & DR & 0.040 & 0.235 & - & Width, conductivity & $0.227^{*}$ & - & - \\
\hline & $\mathrm{BD}$ & 0.161 & 0.362 & - & - & & - & - \\
\hline & PF & 0.231 & 0.626 & - & - & & - & - \\
\hline Common Species & $\mathrm{PF}$ & 0.002 & 0.511 & - & Depth, width, sand & $0.160^{*}$ & - & - \\
\hline
\end{tabular}

Results based on partial redundancy analysis (RDA) analysis. The final pRDA model includes variables retained with the forward selection procedure. $P$ spat and $P$ env give the significance for the full spatial and full environmental models (i.e. using all variables available). The spatial and environmental variables are shown in the order in which they were retained in the forward selection procedure. [a], environmental fraction; [b], shared fraction; [c], spatial fraction. The significance values for the environmental and spatial fractions are given.

DR, Ducke Reserve; BD, Biological Dynamics of Forest Fragments Project; PF, Presidente Figueiredo County.

${ }^{*} \mathrm{p}<0.001 ;-$, Full model not significant.

variables (depth and temperature) were retained and accounted for $14.3 \%$ of the variance in assemblage data. At PF, stream depth, width, temperature and conductivity were the variables retained, accounting for $14.6 \%$ of the variance. The variance explained exclusively by the environment was higher within regions ( $D R=16.6 \%$, $\mathrm{BD}=14.3 \%, \mathrm{PF}=14.6)$ than for pooled data $(11 \%)$. However, the fraction [a $+\mathrm{b}$ ] (environment [a] plus spatially structured environment $[b]$ ) was higher for the pooled data (Table 2).

The removal of rare species did not greatly affect the overall results (Table S1). Our results are in agreement with other studies (e.g. Siqueira et al., 2012) discussing the effect of rare species in metacommunity analyses. We found that results based on common and exclusive species were similar to those presented above, in which there was a prevalence of environmental signals and an absence of significant spatial patterns (Table 3 ).

\section{Discussion}

The three regions differed in environmental characteristics, but the caddisfly assemblage was different only in PF. Both beta-diversity (assemblage composition dispersion) and environmental heterogeneity increased with spatial extent. Thus, as predicted by Anderson (2006), there was a positive association between biological and environmental variability. This association was mediated by spatial extent, because the relative importance of abiotic factors changes across spatial scales (Jackson, Peres-Neto \& Olden, 2001). However, assemblage structure was not better explained by environmental and spatial variables in 
$\mathrm{PF}$, the region with the largest spatial extent and greatest environmental heterogeneity.

Taken as a whole, our results indicate that species sorting appears to predominate over dispersal limitation in determining community composition. For all regions, assemblage structure was better explained by environmental descriptors than by spatial variables. When the analyses were conducted after taking species distributions into account (i.e. sets of common and exclusive species), the results were similar to those for the whole assemblage. At the scales we studied, therefore, it appears that caddisfly species are more dependent on species sorting factors (i.e. relationship between the environmental gradients and species composition) than on dispersal processes. Similar results have been obtained for other freshwater organisms, such as macroinvertebrates (Mykrä, Heino \& Muotka, 2007), snails (Hoverman et al., 2011) and bacterial community composition (Van der Gucht et al., 2007), as well as for terrestrial organisms such as plants (Tuomisto, Ruokolainen \& Yli-Halla, 2003; Gilbert \& Lechowicz, 2004; Ruokolainen et al., 2007), highlighting the 'power of species sorting' mechanisms (Leibold et al., 2004; Van der Gucht et al., 2007). Our results were also consistent with the prediction that 'common' species should be mainly related to environmental gradients. However, we did not find a predominance of spatial factors structuring assemblages of 'exclusive' species. Actually, in one case (DR region), even for 'exclusive species', which according to our initial prediction should be more related to spatial variables, we detected a significant environmental effect.

Geomorphological and hydrological features may account for the differences in assemblage composition between regions in our study. For instance, most streams in the PF region contain bedrock and free stones as the main substrata, whereas most BD and DR streams have sandy bottoms. Stream substratum has been recognised as an important factor controlling the distribution of caddisflies in other regions (Wiggins, 1996; Urbanic, Toman \& Krusnik, 2005), as well as other aquatic insects (Buss et al., 2004; Hepp, Landeiro \& Melo, 2012; Siqueira et al., 2012). In our study, the spatial patterning observed in the analysis using all data may be due to the lack of environmental variables describing regional patterns. Conversely, given that the principal coordinates of neighbour matrices (PCNMs) retained in the pRDA model were those that represent broad spatial scales (first-order PCNMs; Borcard \& Legendre, 2002), one could infer that, at this scale, dispersal becomes a limitation for caddisflies.

The dispersal modes of caddisflies are dependent on their life-cycle stage. Larval stages disperse by drifting downstream, mainly during spate events where the dispersal distance is dependent on spate intensity. Adults are known to disperse upstream and to other streams by lateral flight (Collier \& Smith, 1998). We expected to observe spatial patterns caused by dispersal limitation at least in the PF area, because of its large spatial extent. However, such spatial patterns were not detected. Probably, the lack of spatial effects in the PF region is related to the hydrological characteristics of that area: here streams are wider, with more rapids and higher water velocity, factors that increase the intensity of disturbances during spates. Spates might carry organisms for long distances and obscure the relationship between niche factors and dispersal abilities. At $\mathrm{DR}$ and $\mathrm{BD}$, the streams are smaller and streams overflow laterally during spates, rather than rushing downstream (Pazin et al., 2006; Espírito-Santo et al., 2009).

A number of factors could account for the differentiated fauna found in PF sites. For instance, streams sampled in PF are wider and have less canopy cover than the other two regions, allowing high light availability and algal proliferation (Vannote et al., 1980). Accordingly, most species found in PF feed on algae, including six species of the family Hydroptilidae and three species in the genus Smicridea [Hydropsychidae] (Pes, Hamada \& Soares, 2008) that were found only in PF streams. Atopsyche sp. [Hydrobiosidae] and Synoestropsis sp. [Hydropsychidae], also found only in PF, are generally associated with bedrock substrata of wider streams in Central Amazonia.

We used only environmental variables describing the variation at local scale (stream reaches), and inclusion of regional variables could improve understanding of species distributions and increase the percentage of variance explained (Roque et al., 2010). Galbraith, Vaughn \& Meier (2008) found that 22.4 and $24.2 \%$ of the explained variance in caddisfly species distributions in Oklahoma and Arkansas streams was accounted for exclusively by regional environmental variables and by regional spatially structured variables (shared component), respectively. However, the spatial variables generated with PCNM are expected to form clumps similar to those formed by regional environmental variables. The lack of a spatial component observed within regions indicates that the inclusion of regional environmental variables would probably not help to explain caddisfly species distributions within regions.

Spatial effects were not observed even in PF, the area with the greatest spatial extent. This was unexpected, mainly for exclusive species. The strength of association between geographical distance and assemblage composition depends on grain size and on spatial extent. In general, large spatial extents should produce stronger relationships between assemblage composition and

(C) 2012 Blackwell Publishing Ltd, Freshwater Biology, 57, 1554-1564 
geographical distance (Nekola \& White, 1999). Brown \& Swan (2010) and Heino et al. (2012), in studies carried out at a similar spatial extent (c. $100 \mathrm{~km}$ ), observed low spatial effects and attributed their findings to the possibility that the study regions were too small to detect the strong dispersal limitation. However, Thompson \& Townsend (2006) and Maloney \& Munguia (2011) also analysed data on macroinvertebrates at a similar spatial extent and found greater spatial effects. In Finland, on the other hand, Astorga et al. (2012) found that freshwater organisms are more controlled by environmental factors than by limited dispersal over distances up to $1100 \mathrm{~km}$, even though species with low dispersal abilities were more related to spatial distance. A possible reason for these contrasting results is the differences in the dispersal ability of the fauna sampled in each region where these studies were conducted (i.e. regions dominated by good dispersers are expected to have low spatial signatures). Finally, another possible explanation is that these studies focused on the entire community rather than on a small subset of the freshwater community (e.g. subsets of species with similar dispersal abilities; Brown et al., 2011).

\section{Caveats and perspectives}

Two limitations of our study need to be discussed. Firstly and most importantly, we are aware that our approach to address the issue of teasing apart species sorting from dispersal limitation has some shortcomings. For instance, the presumption that common species can be equated to species with high dispersal capabilities or, conversely, that exclusive species are unequivocally poor dispersers is not easily defensible. The use of molecular data for some species belonging to the metacommunity of interest would certainly be the best option to explore the relationship between local conditions and dispersal limitation in determining local community structure. With these data at hand, one could follow different strategies. One possibility, for example, would consist of using molecular data to calculate the distance matrix entering $\mathrm{PCNM}$ or using the distance matrix directly if one uses a distance-based approach (Tuomisto \& Ruokolainen, 2006). We are of the opinion that this strategy would represent space (the connectivity among the local communities) in a much more reliable way. Second, we did not measure a number of variables that potentially could help explain variation in caddisfly community structure, such as algal biomass (e.g. Wellnitz \& Leroy-Poff, 2006), frequency of disturbances (Matthaei, Arbuckle \& Townsend, 2000; Melo et al., 2003), stream geomorphology (Olsen et al., 2001) and abundance of predators (Wissinger et al., 2006).
However, we emphasise that the environmental predictors we used (water current, discharge, $\mathrm{pH}$, temperature, stream depth and width, and percentage of substrate type) are frequently reported as being of paramount importance in shaping caddisfly community structure (Beisel et al., 1998; Costa \& Melo, 2008). Also, the lack of strong spatial patterning in the communities suggests that the common criticism of metacommunity studies that spatial patterning was a result of some unmeasured and spatially autocorrelated local variable (see Peres-Neto \& Legendre, 2010) cannot be levelled here. Even if a large and significant fraction [c] were found, we could use the recent protocol developed by Diniz-Filho et al. (2012), which aims to evaluate whether this fraction can be attributed to a spatial process or to environmental factors that are missing from the analysis.

Before a particular taxon can be used as an environmental indicator, it is important to evaluate the effects of spatial scale and environmental heterogeneity on differences between assemblages. The movement of aquatic insects via different dispersal routes has received considerable attention (Collier \& Smith, 1998; Bilton et al., 2001). Downstream drift, upstream flight and between-stream migrations through lateral migrations (Miller, Blinn \& Keim, 2002) increase the genetic homogeneity and similarity of species compositions among streams and stream reaches (i.e. decrease beta-diversity). In the absence of environmental effects, the dispersal ability of species is a major control of turnover. Our results show that community composition was related to spatial processes when all sites are analysed jointly. However, when we analysed the data from each region separately, community composition was unrelated to spatial processes (even in PF, which has a spatial extent of more than $110 \mathrm{~km}$, similar to the longest distance of the pooled data). Even when there were significant effects of spatial variables, environmental properties explained much more variation than did the spatial variables. In temperate regions, caddisflies are considered to be useful indicators for biomonitoring, because of their sensitivity to aquatic conditions (Rosenberg \& Resh, 1993). In view of the higher environmental control (i.e. species sorting) observed, our results support the use of caddisflies as an indicator of water quality and environmental conditions, even in megadiverse tropical regions such as the Amazon.

\section{Acknowledgments}

We are very grateful to Neusa Hamada and to Conselho Nacional de Desenvolvimento Científico e Tecnológico (CNPq) for continuously supporting our workgroups by 
providing research grants and student fellowships. This project received partial financial support from PPI 1-3070, 1-3570 (MCT/INPA) and CNPq/Edital Universal (process \# 479258/2001-5) and Project Igarapes (No. 597 Technical Series, Biological Dynamics of Forest Fragments Project PDBFF - INPA/Smithsonian Institution). Thaise Emilio helped with Fig. 1, and two anonymous reviewers provided helpful comments on early drafts. Jéferson Silva helped greatly in the fieldwork.

\section{References}

Anderson M.J. (2001) A new method for non-parametric multivariate analysis of variance. Austral Ecology, 26, 32-46.

Anderson M.J. (2006) Distance-based tests for homogeneity of multivariate dispersions. Biometrics, 62, 245-253.

Anderson M.J., Ellingsen K.E. \& McArdle B.H. (2006) Multivariate dispersion as a measure of beta diversity. Ecology Letters, 9, 683-693.

Astorga A., Oksanen J., Luoto M., Soininen J., Virtanen R. \& Muotka T. (2012) Distance decay of similarity in freshwater communities: do macro- and microorganisms follow the same rules? Global Ecology and Biogeography, 21, 365-375.

Beisel J.N., Usseglio-Polatera P., Thomas S. \& Moreteau J.C. (1998) Stream community structure in relation to spatial variation: the influence of mesohabitat characteristics. Hydrobiologia, 389, 73-88.

Bilton D.T., Freeland J.R. \& Okamura B. (2001) Dispersal in freshwater invertebrates. Annual Review of Ecology and Systematics, 32, 159-181.

Blanchet F.G., Legendre P. \& Borcard D. (2008a) Forward selection of explanatory variables. Ecology, 89, 2623-2632.

Blanchet F.G., Legendre P. \& Borcard D. (2008b) Modelling directional spatial processes in ecological data. Ecological Modelling, 215, 325-336.

Bond N.R. \& Downes B.J. (2000) Flow-related disturbance in streams: an experimental test of the role of rock movement in reducing macroinvertebrate population densities. Marine and Freshwater Research, 51, 333-337.

Borcard D. \& Legendre P. (2002) All-scale spatial analysis of ecological data by means of principal coordinates of neighbour matrices. Ecological Modelling, 153, 51-68.

Borcard D., Legendre P. \& Drapeau P. (1992) Partialling out the spatial component of ecological variation. Ecology, 73, 1045-1055.

Brown B.L. \& Swan C.M. (2010) Dendritic network structure constrains metacommunity properties in riverine ecosystems. Journal of Animal Ecology, 79, 571-580.

Brown B.L., Swan C.M., Auerbach D.A., Grant E.H.C., Hitt N.P., Maloney K.L. et al. (2011) Metacommunity theory as a multispecies, multiscale framework for studying the influence of river network structure on riverine communities and ecosystem. Journal of the North American Benthological Society, 30, 310-327.
Buss D.F., Baptista D.F., Nessimian J.L. \& Egler M. (2004) Substrate specificity, environmental degradation and disturbance structuring macroinvertebrate assemblages in neotropical streams. Hydrobiologia, 518, 179-188.

Cao Y., Larsen D.P. \& Thorne R.S.-J. (2001) Rare species in multivariate analysis for bioassessment: some considerations. Journal of the North American Benthological Society, 20, 144-153.

Clausen B. \& Biggs B.J.F. (1997) Relationships between benthic biota and hydrological indices in New Zealand streams. Freshwater Biology, 38, 317-342.

Collier K.J. \& Smith B.J. (1998) Dispersal of adult caddisflies (Trichoptera) into forests alongside three New Zealand streams. Hydrobiologia, 361, 53-65.

Costa S.S. \& Melo A.S. (2008) Beta diversity in stream macroinvertebrate assemblages: among-site and amongmicrohabitat components. Hydrobiologia, 598, 131-138.

Cottenie K. (2005) Integrating environmental and spatial processes in ecological community dynamics. Ecology Letters, 8, 1175-1182.

Couceiro S.R.M., Hamada N., Luz S.L.B., Forsberg B.R. \& Pimentel T.P. (2007) Deforestation and sewage effects on aquatic macroinvertebrates in urban streams in Manaus, Amazonas, Brazil. Hydrobiologia, 575, 271-284.

Craig D.A. (1987) Some of what you would know about water or K.I.S.S. for hydrodynamics. Bulletin of the North American Benthological Society, 35, 178-182.

Diniz-Filho J.A.F., Siqueira T., Padial A.A., Rangel T.F., Landeiro V.L. \& Bini L.M. (2012) Spatial autocorrelation analysis allows disentangling the balance between neutral and niche processes in metacommunities. Oikos, 121, 201210.

Dray S., Legendre P. \& Blanchet F.G. (2009) packfor: Forward Selection with Permutation (Canoco p.46) (R package version 0.0-7/r58.). Available at: http://R-Forge.R-project.org/pro jects/sedar/. Last accessed 15 May 2012.

Espírito-Santo H.M.V., Magnusson W.E., Zuanon J., Mendonça F.P. \& Landeiro V.L. (2009) Seasonal variation in the composition of fish assemblages in small Amazonian forest streams: evidence for predictable changes. Freshwater Biology, 54, 536-548.

Galbraith H.S., Vaughn C.C. \& Meier C.K. (2008) Environmental variables interact across spatial scales to structure trichopteran assemblages in Ouachita Mountain rivers. Hydrobiologia, 596, 401-411.

Gilbert B. \& Lechowicz M.J. (2004) Neutrality, niches, and dispersal in a temperate forest understory. Proceedings of the National Academy of Sciences of the United States of America, 101, 7651-7656.

Heino J., Grönroos M., Soininen J., Virtanen R. \& Muotka T. (2012) Context dependency and metacommunity structuring in boreal headwater streams. Oikos, 121, 537-544.

Hepp L.U., Landeiro V.L. \& Melo A.S. (2012) Experimental assessment of the effects of environmental factors and longitudinal position on alpha and beta diversities of 
aquatic insects in a neotropical stream. International Review of Hydrobiology, 97, 157-167.

Hoverman J.T., Davis C.J., Werner E.E., Skelly D.K., Relyea R.A. \& Yurewicz K.L. (2011) Environmental gradients and the structure of freshwater snail communities. Ecography, 34, 1049-1058.

Hubbell S.P. (2001) The Unified Neutral Theory of Biodiversity and Biogeography. Princeton University Press, Princeton.

Jackson D.A., Peres-Neto P.R. \& Olden J.D. (2001) What controls who is where in freshwater fish communities - the roles of biotic, abiotic, and spatial factors. Canadian Journal of Fisheries and Aquatic Sciences, 58, 157-170.

Landeiro V.L., Hamada N., Godoy B.S. \& Melo A.S. (2010) Effects of litter patch area on macroinvertebrates assemblage structure and leaf breakdown in Central Amazonian streams. Hydrobiologia, 649, 355-363.

Landeiro V.L., Hamada N. \& Melo A.S. (2008) Responses of aquatic invertebrate assemblages and leaf breakdown to macroconsumer exclusion in Amazonian 'terra firme' streams. Fundamental and Applied Limnology, 172, 49-58.

Landeiro V.L. \& Magnusson W.E. (2011) The geometry of spatial analyses: implications for conservation biologists. Natureza $\mathcal{E}$ Conservação, 9, 7-20.

Landeiro V.L., Magnusson W.E., Melo A.S., Espírito-Santo H.M.V. \& Bini L.M. (2011) Spatial eigenfunction analyses in stream networks: do watercourse and overland distances produce different results? Freshwater Biology, 56, 1184-1192.

Legendre P., Borcard D. \& Peres Neto P.R. (2005) Analyzing beta diversity: partitioning the spatial variation of community composition data. Ecological Monographs, 75, 435450.

Leibold M.A., Holyoak M., Mouquet N., Amarasekare P., Chase J.M., Hoopes M.F. et al. (2004) The metacommunity concept: a framework for multi-scale community ecology. Ecology Letters, 7, 601-613.

Logue J.B., Mouquet N., Peter H. \& Hillebrand H. (2011) Empirical approaches to metacommunities: a review and comparison with theory. Trends in Ecology E Evolution, 26, 482-491.

Maloney K.O. \& Munguia P. (2011) Distance decay of similarity in temperate aquatic communities: effects of environmental transition zones, distance measure, and life histories. Ecography, 34, 287-295.

Matthaei C.D., Arbuckle C.J. \& Townsend C.R. (2000) Stable surface stones as refugia for invertebrates during disturbance in a New Zealand stream. Journal of the North American Benthological Society, 19, 82-93.

McCreadie J.W. \& Colbo M.H. (1991) Spatial distribution patterns of larval cytotypes of the Simulium venustum/verecundum complex (Diptera: Simuliidae) on the Avalon Peninsula, New found land: factors associated with occurrence. Canadian Journal of Zoology, 69, 2651-2659.

Melo A.S., Niyogi D.K., Matthaei C.D. \& Townsend C.R. (2003) Resistance, resilience, and patchiness of invertebrate assemblages in native tussock and pasture streams in New
Zealand after a hydrological disturbance. Canadian Journal of Fisheries and Aquatic Sciences, 60, 731-739.

Miller M.P., Blinn D.W. \& Keim P. (2002) Correlations between observed dispersal capabilities and patterns of genetic differentiation in populations of four aquatic insect species from the Arizona White Mountains, USA. Freshwater Biology, 47, 1660-1673.

Mykrä H., Heino J. \& Muotka T. (2007) Scale-related patterns in the spatial and environmental components of stream macroinvertebrate assemblage variation. Global Ecology and Biogeography, 16, 149-159.

Nekola J.C. \& White P.S. (1999) The distance decay of similarity in biogeography and ecology. Journal of Biogeography, 26, 867-878.

Oksanen J., Blanchet F.G., Kindt R., Legendre P., O'Hara R.B., Simpson G.L. et al. (2011) vegan: Community Ecology Package (R package version 1.17-6). Available at: http://CRAN.Rproject.org/package=vegan. Last accessed 20 January 2011.

Olsen D.A., Townsend C.R. \& Matthaei C.D. (2001) Influence of reach geomorphology on hyporheic communities in a gravel-bed stream. New Zealand Journal of Marine and Freshwater Research, 35, 181-190.

Pazin V.F.V., Magnusson W.E., Zuanon J. \& Mendonça F.P. (2006) Fish assemblages in temporary ponds adjacent to 'terra-firme' streams in Central Amazonia. Freshwater Biology, 51, 1025-1037.

Peres-Neto P.R. \& Legendre P. (2010) Estimating and controlling for spatial structure in the study of ecological communities. Global Ecology and Biogeography, 19, 174-184.

Peres-Neto P.R., Legendre P., Dray S. \& Borcard D. (2006) Variation partitioning of species data matrices: estimation and comparison of fractions. Ecology, 87, 2614-2625.

Pes A.M.O., Hamada N. \& Soares C.C. (2008) Description of the last-instar larva and pupa and the bionomics of Smicridea (Smicridea) truncata Flint (Trichoptera: Hydropsychidae) in Central Amazonia, Brazil. Zootaxa, 1732, 54-60.

Petersen I., Masters Z., Hildrew A.G. \& Ormerod S.J. (2004) Dispersal of adult aquatic insects in catchments of differing land use. Journal of Applied Ecology, 41, 934-950.

R Development Core Team (2011) R: A Language and Environment for Statistical Computing (2.12.1). R Foundation for Statistical Computing, Vienna, Austria. Available at: http:/ / www.R-project.org. Last accessed 12 May 2011.

Roque F.O., Siqueira T., Bini L.M., Ribeiro M.C., Tambosi L.R., Ciocheti G. et al. (2010) Untangling associations between chironomid taxa in Neotropical streams using local and landscape filters. Freshwater Biology, 55, 847-865.

Rosenberg D.M. \& Resh V.H. (1993) Freshwater Biomonitoring and Benthic Macroinvertebrates, pp. 1-488. Chapman \& Hall, New York.

Ruokolainen K., Tuomisto H., Macía M.J., Higgins M.A. \& Yli-Halla M. (2007) Are floristic and edaphic patterns in Amazonian rain forests congruent for trees, pteridophytes and Melastomataceae? Journal of Tropical Ecology, 23, 13-25. 
Sioli H. (1984) The Amazon and its main affluents: hydrography, morphology of the river courses, and river types. In: The Amazon. Limnology and Landscape Ecology of a Mighty Tropical River and its Basin, pp. 127-165. Dr. W. Junk Publishers, Boston.

Siqueira T., Bini L.M., Roque F.O., Couceiro S.R.M., TrivinhoStrixino S. \& Cottenie K. (2012) Common and rare species respond to similar niche processes in macroinvertebrate metacommunities. Ecography, 35, 183-192.

Thompson R.M. \& Townsend C.R. (2006) A truce with neutral theory: local deterministic factors, species traits and dispersal limitation together determine patterns of diversity in stream invertebrates. Journal of Animal Ecology, 75, 476-484.

Tuomisto H. \& Ruokolainen K. (2006) Analyzing or explaining beta diversity? Understanding the targets of different methods of analysis. Ecology, 87, 2697-2708.

Tuomisto H., Ruokolainen K. \& Yli-Halla M. (2003) Dispersal, environment, and floristic variation of western Amazonian forests. Science, 299, 241-244.

Urbanic G., Toman M.J. \& Krusnik C. (2005) Microhabitat type selection of caddisfly larvae (Insecta: Trichoptera) in a shallow lowland stream. Hydrobiologia, 541, 1-12.

Van der Gucht K., Cottenie K., Muylaert K., Vloemans N., Cousin S., Declerck S. et al. (2007) The power of species sorting: local factors drive bacterial community composition over a wide range of spatial scales. Proceedings of the National Academy of Sciences of the United States of America, 104, 20404-20409.

Vannote R.L., Minshall G.W., Cummins K.W., Sedell J.R. \& Cushing C.E. (1980) The River Continuum Concept. Canadian Journal of Fisheries and Aquatic Sciences, 37, 130-137.

Wellnitz T. \& Leroy-Poff N. (2006) Herbivory, current velocity and algal regrowth: how does periphyton grow when the grazers have gone? Freshwater Biology, 51, 21142123.

Wiggins G.B. (1996) Larvae of the North American Caddisfly Genera (Trichoptera), pp. 1-457. University of Toronto Press, Toronto.

Wilcock H.R., Bruford M.W., Nichols R.A. \& Hildrew A.G. (2007) Landscape, habitat characteristics and the genetic population structure of two caddisflies. Freshwater Biology, 52, 1907-1929.

Wissinger S.A., Whissel J.C., Eldermire C. \& Brown W.S. (2006) Predator defence along a permanent gradient: roles of case structure, behavior, and developmental phenology in caddisflies. Oecologia, 147, 667-678.

\section{Supporting Information}

Additional Supporting Information may be found in the online version of this article:

Table S1. Variation partitioning results after removing rare species (i.e. species that occurred in one to 10 streams).

As a service to our authors and readers, this journal provides supporting information supplied by the authors. Such materials are peer-reviewed and may be re-organized for online delivery, but are not copy-edited or typeset. Technical support issues arising from supporting information (other than missing files) should be addressed to the authors.

(Manuscript accepted 3 May 2012) 